\title{
PENDUgAAN MUSIM PEMIJAHAN ABALON (Haliotis asinina) DI PANTAI KUTA, LOMBOK TENGAH
}

\author{
Ketut Maha Setiawati"), Yunus"), Irwan Setyadi") dan \\ Rosliwati Arfah")
}

\begin{abstract}
ABSTRAR
Penelitian ini bertujuan untuk mengetahui musim pemijahan abalon. Induk abalon diperoleh dari nelayan di pantai Kuta, Lombok Tengah. Variabel yang diamati yaitu panjang cangkang, berat tubuh, panjang gonad, panjang hepatopankreas dan diameter telur. Sampel diambil pada musim yang berbeda yaitu pada bulan Juli, Oktober, Januari dan Februari. Hasil penelitian menunjukkan persentase penutupan gonad terhadap hepatopankreas lebih dari 50\% terdapat pada bulan Juli, Oktober, Januari dan Februari. Diameter telur lebih dari $100 \mu \mathrm{m}$ terdapat pada bulan Juli dan Oktober. Nilai regresi linier tertinggi yang terjadi pada bulan Oktober. Dari hasil pengamatan diduga abalon di alam memijah sepanjang tahun namun puncak musim pemijahan terjadi pada bulan Juli dan Oktober.
\end{abstract}

ABSTRACT: Estimation of Spawning Seasons of Abalone (H. arinina) at Kuta Bey, Central Lombol, by: Ketut Maba Setiowati, Ywuns, Irwosn Setyadi, and Roslivwati Arfab.

The purpose of the experiment was to know spawning seasons of the abalons. The wild broodstock abalons were obtained from fishermen at Kuta bay (Central Lombok). The variable measured were shell length, body weight, length of gonad, length of hepatopancreas and diameter of egg. The samples were taken at different seasons on July, Oktober, January and February.

The result of observation showed that the percentage of gonad covering hepatopancreas which were more than $50 \%$ appeared on July, Oktober, January and February. The diameter of $\mathrm{egg}$ which were more than $100 \mu \mathrm{m}$ were observed on July and Oktober. The highest linear regresion appeared on October. The finding suggested that the spawning seasons of abalons occured throughout a year, but the peak were on July and October.

KEYWORDS: Abalone, sparening season, gonad mesuration

\section{PENDAHULUAN}

Pemanfaatan sumber daya laut tidak hanya dilakukan melalui penangkapan, tetapi juga perlu dikembangkan usaha budidayanya. Pengembangan usaha budidaya abalon dimasa datang mempunyai prospek cukup cerah, mengingat beberapa keunggulan yang dimilikinya baik dari teknik budidaya, potensi lahan, dan aspek pemasarannya. Abalon merupakan satu jenis kekerangan yang

") Peneliti pada Loka Penelitian Perikanan Pantai, Gondol 
mempunyai nilai ekonomis penting. Pada tahun 1990 abalon diekspor dalam bentuk kering, asin maupun dalam air garam yaitu dari Sulawesi Selatan sejumlah $31.621 \mathrm{~kg}$ dengan negara tujuan Jepang, Hongkong dan Singapura (Direktorat Jenderal Perikanan, 1991).

Sampai saat ini produksi abalon masih berasal dari hasil penangkapan di alam. Meningkatnya kebutuhan akan abalon dapat mendorong usaha penangkapan secara intensif sehingga populasi abalon di alam berkurang. Di samping itu, pertumbuhan abalon sangat lambat (Imai, 1977). Oleh karena itu, untuk menjaga kelestarian populasinya perlu dilakukan penelitian mengenai beberapa aspek biologinya termasuk musim pemijahan.

Tujuan dari penelitian ini adalah untuk mengetahui musim pemijahan dengan pengamatan meliputi data panjang dan lebar cangkang, bobot tubuh, diameter telur, panjang gonad dan panjang hepatopankreas.

\section{BAHAN DAN METODE}

Pengelompokan spesies abalon ini didasarkan pada bentuk cangkang dan alur-alurnya (Abott and Dance, 1980; Dharma, 1988).

Penelitian dilakukan dengan cara mengambil sampel di alam yaitu dari Pantai Kuta, Lombok Tengah pada musim hujan (Januari), awal musim kemarau (Februari), musim kemarau (Juli) dan awal musim hujan (Oktober). Abalon hasil tangkapan di alam dikumpulkan dalam jumlah yang cukup yaitu lebih dari 30 individu dan ditempatkan dalam coolbox kemudian diangkut ke Gondol dan dilakukan analisis di laboratorium. Peubah yang diamati adalah bobot tubuh, panjang cangkang, panjang gonad, panjang hepatopankreas dan diameter telur. Abalon yang digunakan mempunyai panjang cangkang 3,4-9,0 cm.

Tingkat kematangan gonad ditentukan berdasarkan persentase penutupan ovari terhadap hepatopankreas pada bagian posterior. Persentase penutupan tersebut dibedakan menjadi 4 kelompok yaitu $0-10 \%, 11-25 \%, 26-50 \%$ dan lebih dari $50 \%$. Gonad dapat dilihat dengan cara membuka pada bagian posterior antara otot kaki dan cangkang dengan tangan. Testis berwarna putih susu dan mudah dibedakan dengan bagian hepatopankreas, ovari berwarna hijau gelap dan agak sulit dibedakan dari hepatopankreas (Singhagraiwan and Doi, 1992). Pengamatan ini dapat dilakukan tanpa mematikan contoh yang diamati.

\section{HASIL DAN BAHASAN}

\section{Aspek Biologi Abalon}

Pada Table 1 terlihat bahwa abalon jantan lebih banyak daripada abalon betina dengan perbandingan jantan dan betina 1:0,7 pada setiap pengambilan sampel. Menurut Singhagraiwan and Doi (1992), perbandingan abalon jantan 
dan betina di alam sekitar 1:1. Pada Table 1 tersebut tampak juga bahwa gonad jantan mulai berkembang pada panjang cangkang $3,4 \mathrm{~cm}$ bahkan terkadang pada panjang cangkang $3,2 \mathrm{~cm}$ gonad jantan sudah mulai berkembang. Sedangkan gonad betina mulai berkembang pada panjang cangkang $4,3 \mathrm{~cm}$. Singhagraiwan and Doi (1992) menyatakan bahwa ukuran minimum biologis (biological minimum size) pada abalon betina yaitu pada panjang cangkang 4,4 cm.

Table 1. Number of male and female in each interval of shell length during experiment

\begin{tabular}{ccccccccc}
\hline $\begin{array}{c}\text { Interval of } \\
\text { sbell length } \\
(\mathrm{cm})\end{array}$ & \multicolumn{2}{c}{ July } & \multicolumn{2}{c}{ October } & January & \multicolumn{2}{c}{ February } \\
\cline { 2 - 8 } & Female & Male & Female Male & Female Male & Female & Male \\
\hline $3.4-5.2$ & 1 & 5 & 6 & 7 & 7 & 13 & 1 & 1 \\
$3.4-7.1$ & 20 & 32 & 13 & 17 & 34 & 48 & 23 & 33 \\
$7.2-9.0$ & 16 & 10 & 3 & 4 & 4 & 1 & 0 & 0 \\
\hline
\end{tabular}

\section{Diameter Telur}

Pada Figure 1 terlihat bahwa diameter telur yang melebihi dari $100 \mu \mathrm{m}$ ditemukan pada abalone yang diamati pada bulan Juli dan Oktober, sedangkan pada bulan Januari dan Februari tidak ditemukan diameter telur yang lebih dari $100 \mu \mathrm{m}$. Singhagraiwan and Doi (1992) menyatakan bahwa H.asinina

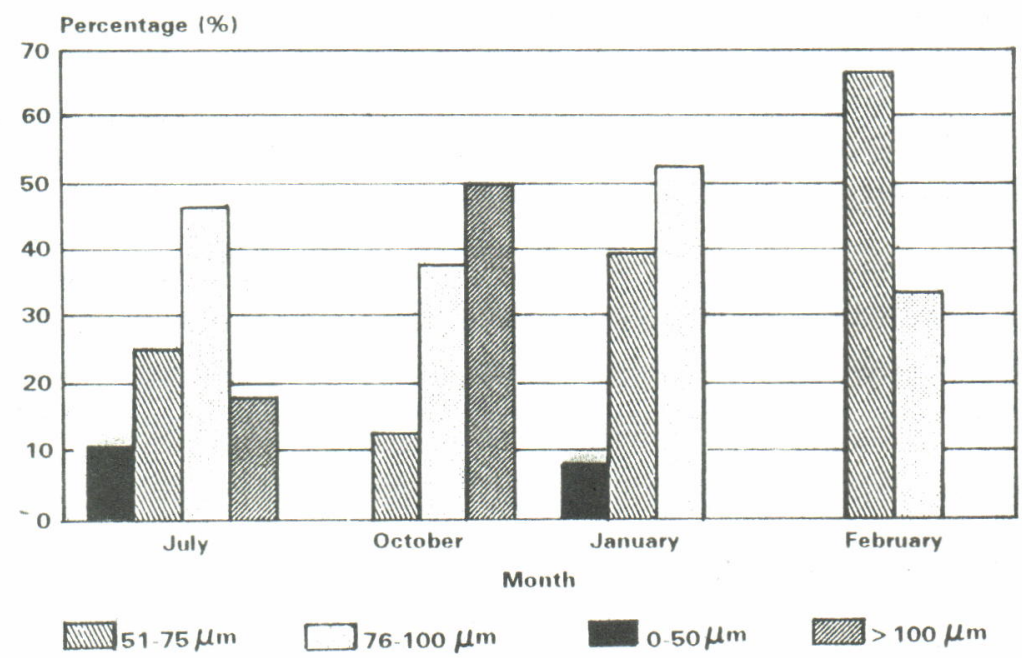

Figure 1. Percentage number of abalone according to egg diameter 
mempunyai diameter telur yang fertil $190 \mu \mathrm{m}$. Dari hasil penelitian pemijahan abalon dengan berbagai rangsangan di Loka Penelitian Perikanan Pantai Gondol diperoleh hasil bahwa diameter telur hasil pemijahan dengan rangsangan ultraviolet yaitu $183 \mu \mathrm{m}$ (Setiawati et al., 1994, unpublisbed). Abalon merupakan salah satu hewan dioecious di mana pembuahannya terjadi di luar tubuhnya. Proses pemijahan ditandai dengan keluarnya sperma dari induk jantan kemudian diikuti oleh keluarnya telur dari induk betina (Fallu, 1991).

\section{Perkembangan Gonad}

Persentase penutupan gonad terhadap hepatopankreas dibedakan menjadi 4 yaitu $0-10 \%, 11-25 \%, 26-50 \%$ dan lebih dari 50\%. Pada Figure 2. terlihat bahwa persentase penutupan gonad yang lebih dari $50 \%$ terdapat pada bulan Juli 38,1\%, Oktober 40\%, Januari 10,3\% dan Februari 16,1\%. Karena persentase penutupan gonad terhadap hepatopankreas yang lebih dari $50 \%$ paling banyak terdapat pada bulan Juli dan Oktober maka dengan demikian diduga bahwa H.asinina memijah pada setiap pengambilan sampel yaitu pada bulan Juli, Oktober, Januari dan Februari, dengan puncak pemijahan sekitar bulan Juli dan Oktober.

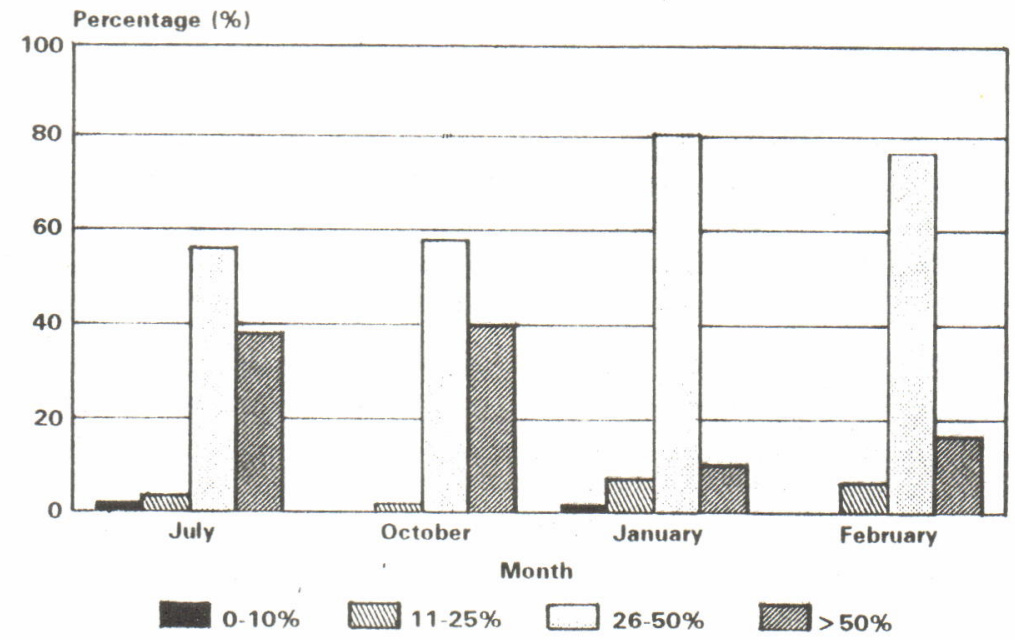

Figure 2. Percentage number of abalone according to gonad coverage

Kematangan gonad dapat terjadi sepanjang tahun, tetapi di alam umumnya dijumpai pada bulan April dan Oktober, abalon mampu memijah 2-3 kali dalam setahun (Fallu, 1991). Menurut Bardach et al. (1972) H.discus umumnya memijah pada suhu $15-20^{\circ} \mathrm{C}$ selama bulan Agustus-Oktober. Di Jepang utara Haliotis diversicolor memijah pada bulan Juni-November. 
Dari hasil pengamatan terlihat bahwa pada abalon dengan panjang cangkang antara $4-9 \mathrm{~cm}$ jarang sekali ditemukan gonad yang kosong. Dengan demikian dapat diduga bahwa H.asinina memijah sepanjang tahun. Menurut Ino dan Harada dalam Ino (1980) abalon mempunyai perkembangan gonad yang baik sepanjang tahun.

\section{Hubungan Panjang-Bobot}

Dari hasil perhitungan regresi linier dengan persamaan $\log W=\mathbf{a}+\mathbf{b} \log \mathrm{L}$; di mana $\mathrm{W}=$ bobot tubuh (gram), $\mathrm{L}=$ panjang cangkang $(\mathrm{cm})$, a dan $\mathrm{b}$ adalah konstanta, diperoleh hasil bahwa urutan nilai b paling tinggi terdapat pada bulan Oktober, nilai tersebut relatif lebih tinggi daripada bulan Juli, kemudian bulan Januari dan Februari. Nilai tersebut dapat dilihat pada Table 2.

Table 2. Value of $a, b$ in $\log W=a+b \log L$

\begin{tabular}{lrcc}
\hline \multicolumn{1}{c}{ Montb } & Antilog $\boldsymbol{a}$ & $\boldsymbol{b}$ & $\boldsymbol{r}$ \\
\hline July & 2.388 & 1.635 & 0.662 \\
October & 0.209 & 2.780 & 0.966 \\
January & 13.677 & 0.455 & 0.312 \\
February & 14.723 & 0.346 & 0.308 \\
\hline
\end{tabular}

Pada ikan apabila nilai $\mathrm{b}<3$ maka pertambahan panjang tidak seimbang dengan pertambahan bobotnya, pertambahan beratnya tidak secepat pertambahan panjangnya. Jika $b=3$ maka pertambahan panjang dan pertambahan bobotnya seimbang. Jika $b>3$ dapat ditafsirkan bahwa pertambahan panjang ikan tidak secepat pertambahan bobotnya (Effendie, 1979).

Jika dilihat dari Table 2, nilai b yang paling tinggi terdapat pada bulan Oktober, maka pertambahan bobot yang paling cepat adalah pada bulan Oktober kemudian Juli, Januari dan Februari. Menurut Uki (1989), hubungan panjang dan bobot H.discus Hannai pada panjang cangkang $1.9 \mathrm{~cm}$ diperoleh nilai sebagai berikut $\mathrm{W}=0,14 \mathrm{~L}^{3}$. Nilai tersebut lebih mendekati nilai pada bulan Oktober. Menurut Effendie (1979), di dalam proses reproduksi, sebelum terjadi pemijahan sebagian besar hasil metabolisme tertuju untuk perkembangan gonad. Gonad bertambah berat dibarengi dengan semakin bertambah besar ukurannya termasuk garis tengah telurnya.

\section{Habitat}

Tempat pengambilan sampel abalon adalah di Pantai Kuta, Lombok Tengah. Pantai tersebut tidak terdapat sumber air tawar (sungai), berpasir putih, dan di kawasan tersebut terdapat berbagai jenis rumput laut seperti Eucheuma, 
Gracilaria, Ulva, Dictyota, Hypnea, dan lain-lain. Abalon terdapat di perairan pantai berkarang di laut terbuka mulai dari tepi perairan pantai yang dangkal sampai kedalaman 20m. Fallu (1991) menyatakan bahwa abalon memakan berbagai rumput laut, tetapi abalon alam lebih menyukai alga merah, kemudian alga cokelat dan sedikit alga hijau, abalon termasuk herbivora.

Di beberapa perairan lain seperti Pantai Dusun Batu Kijuk, Sekotong, Lombok Barat dan Pantai Nusa Lembongan, Bali, yang mempunyai habitat sama dengan Pantai Kuta, H.asinina juga mendominasi jenis-jenis abalon lain (Table 3).

Table 3. Dominant species of abalone in Lombok and Bali Islands

\begin{tabular}{ll}
\hline \multicolumn{1}{c}{ Species } & \multicolumn{1}{c}{ Location } \\
\hline H. asinina & Kuta, Central Lombok \\
H. asinina & Sekotong, West Lombok* \\
H. asinina & Nusa Lembongan, Bali \\
H. squamata & Pekutatan, Bali \\
\hline * no seaweed culture in this location
\end{tabular}

Jika dilihat jenis abalon yang terdapat di desa Pekutatan Bali, dengan pantai yang berpasir hitam, berpantai terjal, dan terdapat sumber air tawar, rumput laut yang banyak terdapat yaitu Galaxea dan sedikit Dictyota. Di pantai tersebut tidak ditemukan abalon jenis H.asinina tetapi dari jenis lain yang diduga H.squamata. Di pulau Moyo Sumbawa juga terdapat jenis abalon tetapi bukan H.asinina, pada lokasi tersebut terdapat sumber air tawar yang kecil, pantai landai, berkarang dan berpasir putih. Dengan demikian dapat dikatakan bahwa masing-masing jenis abalon mempunyai habitat yang spesifik.

Data kualitas air pada musim hujan dan kemarau di pantai Kuta menunjukkan bahwa salinitas berkisar antara 35-37\%, pH 7,83-7,85, $\mathrm{NO}_{2}$ 0,006-0,021 ppm, $\mathrm{NH}_{3}$ 0,039-0,083ppm dan $\mathrm{PO}_{4}$ 0,095-0,156ppm.

\section{KESIMPULAN}

Musim pemijahan Haliotis asinina di Pantai Kuta terjadi pada bulan Juli, Oktober, Januari dan Februari, namun puncak musim pemijahan terjadi sekitar bulan Juli dan Oktober. Hal tersebut didukung dari data diameter telur dan persentase penutupan gonad. 
Ketut Maha Setiawati, Yunus, Irwan Setyadi dan Rosliwati Arfah

\section{dAFTAR PUSTAKa}

Abott, R.T. and P. Dance. 1980. Compedium of seashells. E.P. Dutton, New York.

Bardach, J.E., J.H. Ryther and W.O. McLarney. 1972. Aquaculture. The farming and husbandry of freshwater and marine organisms. John Wiley $8 x$ Sons. New York. p 777-785.

Dharma, B. 1988. Siput dan Kerang Indonesia. PT. Sarana Graha, Jakarta. 99p.

Direktorat Jenderal Perikanan. 1991. Statistik ekspor dan impor hasil perikanan 1989. Direktorat Jenderal Perikanan, Departemen Pertanian, Jakarta.

Effendie, M.I. 1979. Metoda biologi perikanan. Yayasan Dewi Sri, Bogor. 112p.

Fallu, R. 1991. Abalon farming. Fishing News Book, Australia. 196 p.

Imai, T. 1977. Aquaculture in shallow seas, progress in shallow sea culture. Oxford \& IBH Publishing Co, New Delhi. 615 p.

Ino, T. 1980. Abalon and their industri in Japan. Japan Marine Products Photo Material Association. Japan. p 165-198.

Singhagraiwan, T. and M. Doi. 1992. Seed production and culture of a tropical abalon, Haliotis asinina Linne. The Research Project of Fishery Resource Development in the Kingdom of Thailand, Thailand. 32 p.

Setiawati, K.M., D. Makatutu dan I. Rusdi. 1994. Studi Pendahuluan Pemijahan Abalon. Loka Penelitian Perikanan Pantai Gondol (unpublished)

Uki, N. 1989. Abalon seedling production and its theory. Int. J. Aq. Fish Technol Vol. 1. National Research Institute of Aquaculture Fisheries Agency. Japan. p 224-231. 